\title{
Research on the Construction of Guangdong-HongKong-Macao Big Bay Smart Tourism Ecospheric Circle
}

\author{
Jian Chen* \\ International Business Faculty \\ Beijing Normal University, Zhuhai \\ Zhuhai, P.R.China
}

\author{
Xinli Zhang \\ International Business Faculty \\ Beijing Normal University, Zhuhai \\ Zhuhai, P.R.China
}

\author{
Ziying Yan \\ International Business Faculty \\ Beijing Normal University, Zhuhai \\ Zhuhai, P.R.China
}

\begin{abstract}
Under the background of the rise of the "Internet +" and the Chinese government's efforts to promote the integrated development of the Bay Area of Guangdong-HongKong-Macao, this paper proposes to integrate the tourism industry of the three areas to create a balanced and stable smart Tourism Ecospheric Circle. The authors propose a basic framework comprised by four basic dimensions: environmental protection, service dimension, market dimension, and information dimension. The construction of a smart tourism ecosystem in the Big Bays combines huge amount of tourism resources and information. Thus, in order to adjust the construction and enhance the quality and value of the tourism industry, measures should be taken seriously to adjust the different political laws and regulations, levels of city digitization development, and endeavour to provide sufficient technical personnel.
\end{abstract}

Keywords-Smart Tourism, Big Data, Internet+Tourism, Tourism Ecosphere, Guangdong-HongKong-Macao Region

\section{INTRODUCTION}

The Great Bay Area of Guangdong, Hong Kong and Macao is a city group consisting of nine cities in the Pearl River Delta, including Guangzhou, Shenzhen, Zhongshan, Jiangmen, Zhaoqing, Dongguan, Foshan, Huizhou and Zhuhai, as well as two special administrative regions, Hong Kong and Macao. With a huge population, more than 66 million permanent residents and 30 million floating population, this Area has jumped to one of the largest Bay areas in the world.

The development of this Area depends strongly on the policy support from the government. At the same time, the growing maturity of Internet technology makes it possible to scientifically build an Intelligent Tourism ecosphere here. This will not only promote its integration and innovation of Internet industry and tourism industry, integrate and coordinate the development and optimization of tourism resources, but also develop and strengthen its new Internet tourism enterprises.
On the Hong Kong side, mainland visitors to Hong Kong are an important part of Hong Kong's tourism and a strong guarantee for its development.

\section{ECOSPHERE OF TOURISM}

Guangdong, Hong Kong and Macao live close to each other. They share the same roots and have similar language and customs. Building an Intelligent Tourism ecosphere can inject new impetus into the development of tourism in the region, and help to enhance the comprehensive strength and competitiveness of the tourism industry in the Great Bay Area.

\section{INTELLIGENT TOURISM ECOSPHERE}

\section{A. Dimensions and Principles}

Firstly, environmental protection refers to the industrial environment in the construction of tourism ecosphere in Guangdong, Hong Kong and Macao, including not only the ecological environment, but also the economic and political environment.

Secondly, service maintenance refers to the use of Internet technology to promote the construction of infrastructure of Intelligent Tourism ecosphere in Guangdong-HongKong-Macao Big Bay District, and ultimately to improve the quality and wisdom of tourism services to tourists.

Thirdly, market dimension refers to a new form of integration of Internet industry connectivity and cross-border tourism industry in Guangdong-HongKong-Macao District.

Fourthly, information dimension refers to the processing and transmission of information generated by tourism industry in Dawan District of Guangdong-HongKong-Macao by means of Internet platform and technology. Information plays an important role in the four dimensions. Through the application of modern technology such as big data and cloud computing, the system collects analyses and processes all kinds of massive information such as digital, audio and video in the state circle. 
In other words, it provides accurate and real-time information services and knowledge services for both consumers and managers through the network platform.

\section{B. Principles of Construction}

Firstly, we should integrate the elements of tourism in the Bay Area, and integrate the six elements of food, shelter, travel, shopping and entertainment in the traditional tourism industry. Join the "Internet + " thinking, and enhance the quality of tourism products and tourism services in the bay area through data analysis and cloud computing.

Secondly, enhance the tourism function of the Bay area, optimize and upgrade the tourism industry ecosphere. Through the effective integration of upstream and downstream enterprises in the tourism industry chain, the tourism quality can be improved.

Thirdly, we should establish industrial clusters in Bay areas, integrate tourism industry with other industries in depth, form tourism-related industrial clusters, and give full play to the advantages of scale, capital and cost.

Fourthly, we should extend the chain of tourism industry in the Bay Area and establish an ecological circle circulation system. In the tourism industry chain, products, funds and information are constantly flowing and transmitted. Finally, the tourism industry ecosphere will be formed based on product starting point, information technology and capital driving.

\section{Construction of Intelligent Tourism Ecosphere}

Based on Yuan Zheng's latitude theory, this paper analyses the construction of tourism wisdom ecosphere in Guangdong-HongKong-Macao Big Bay from four aspects: environment dimension, service dimension, market dimension and information dimension. Fig. 1 is the ecosphere dimension model.

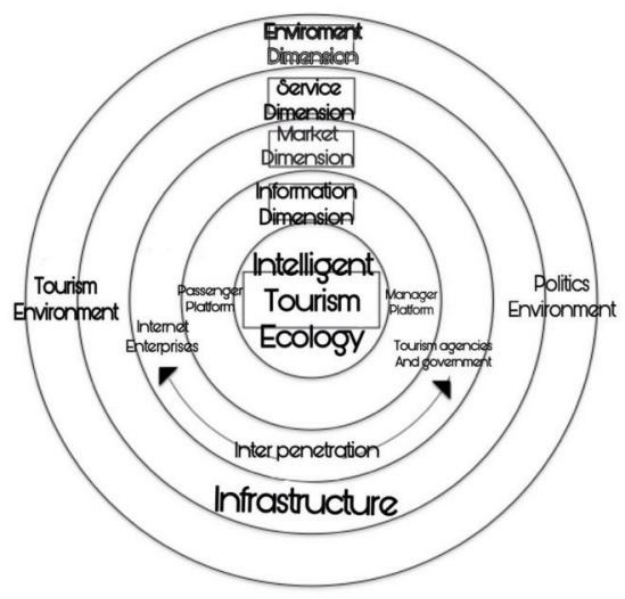

Fig. 1. Dimensional Model of Intelligent Tourism Ecosphere

- Construction of Environmental Dimension. Tourist environment refers to all kinds of tourism resources, such as the natural ecological landscape and recreational facilities in the Bay Area. The differences are significant and complementary.
- Construction of Service Dimension. Service quality and service level is the core of the construction of Intelligent Tourism ecosphere in Dawan District. Consumers' satisfaction is the service goal. Intelligent tourism products and services in food, housing, entertainment and shopping are created for tourists by integrating traditional tourism and modern technology and information technology.

- Construction of Market Dimension. The rapid development of Internet information technology has accelerated the penetration of the concept of "Internet + industry", and the emergence of new internet tourism enterprises has brought about the concept of smart tourism.

- Construction of Information Dimension. The large amount of tourism information is the basic element to build and support the whole ecosphere. The data of this information can come from the aspects of food, accommodation, travel, government organizations, scenic spots, tourists and so on in the Great Bay Area.

The authors believe that the first step of building an independent data collection and processing platform is to divide it into two aspects: tourist platform and manager platform.

Tourist platforms include travel reservation platforms, online and offline interactive experience platforms, passenger evaluation platforms, and passenger complaint platforms. These platforms can run through the whole journey of tourists, covering all aspects and related data, so as to provide real-time tourism information for tourists in the Bay Area. Management platform includes Tourism Emergency Command Platform, Tourism Flow Monitoring System, and Tourism Big Data Platform, etc.

\section{BUILDING INTELLIGENT TOURISM ECOSPHERE}

\section{A. Advantage}

Transportation in the Guangdong-HongKong-Macao Big Bay is very convenient with a large number of airports, a nine-vertical and three-horizontal expressway network and urban light rail. China's Pearl River Delta has surpassed Tokyo as the world's largest metropolitan area in terms of size and population, according to the World Bank's report "Changing Urban Prospects in East Asia: Measuring Ten-Year Spatial Growth" released in 2015 [2]. The airport passenger volume of Guangdong-HongKong-Macao Big Bay is also far higher than that of New York, San Francisco and Tokyo Bay.

\section{B. Disadvantage}

First, the industrial structure of Guangdong-HongKong-Macao Big Bay is not reasonable. Although the total economic development of the District is huge, it relies too much on the secondary industry, and lacks the basic platform of tourism and the ability of scientific and technological innovation.

Second, it is difficult to coordinate within the Great Bay Area. Due to the inherent differences in politics, economy and culture formed in the long history, the Guangdong-HongKong-Macao Big Bay has the most complex 
regional structure and the greatest internal differences. Although the cooperation among the three regions has been successful in recent years, there are still many problems and obstacles to improve and optimize the cooperation between the three regions, such as the sharing of tourism information, endorsement, unified dispatch and so on.

\section{Opportunity}

The construction of Intelligent Tourism ecosphere brings new opportunities to the Big Bay.

First, it has brought about new upgrades in industrial structure and transformation. Guangdong's tourism industry is facing further industrial restructuring. In order to improve its development potential, further reforms must be taken. Due to the competition of land resources in Hong Kong, the surging number of inland tourists in recent years has exerted considerable pressure on Hong Kong's residents. The Macao government is also actively developing the local tourism industry in an attempt to establish a world-class tourism and leisure center. Guangdong, Hong Kong and Macao have jointly developed and cooperated to promote the optimization of industrial structure.

Secondly, it will contribute to the innovation of tourism industry in Guangdong, Hong Kong and Macao. With the rapid development of big data in modern society and the opening of the Internet, the access to tourism market information becomes more and more convenient, and the monopoly of tourism producers on the market no longer exists. At the same time, because of the new technology and more convenient way of payment and consumption, the cost of products has been greatly reduced. Taking the way of traveling as an example, the mode of traveling with groups has been replaced by the mode of traveling freely, and it has become the most important mode of traveling for the Chinese people. Tourism experience and personalization have become the mainstream choice.

When the tourism platform based on big data is established, the information of tourism resources can be displayed efficiently. It can not only make tourism products more ornamental and experiential, but also promote the intelligent exchange of tourists and resources.

\section{Challenges}

The construction of Intelligent Tourism ecosphere brings not only opportunities but also challenges for Guangdong-HongKong-Macao Big Bay, such as the synchronous development of information technology, political and cultural differences. These are the challenges that the development of the Bay Area will encounter, so the authors give two suggestions.

The level of tourism informatization varies from city to city. Taking the number of Internet enterprises and public information as examples, Hong Kong, Macao, Guangzhou and Shenzhen have absolute advantages over other cities in the Pearl River Delta. Especially for the underdeveloped areas such as northern Guangdong and Western Guangdong, the phenomenon of unbalanced economic development is particularly obvious.
The construction and development of Intelligent Tourism ecosphere in Guangdong-HongKong-Macao Big Bay urgently need relevant technical personnel covering many disciplines, such as tourism, information technology, network, and data mining and so on.

\section{PROPOSAL}

The key to balanced development is to increase investment, attract regions and enterprises with good Internet foundation and mature development conditions to strengthen cooperation with regions and enterprises, and force enterprises to increase investment in information infrastructure with data application and data value.

The platform construction and operation of intelligent ecosphere need technology and talents. On the one hand, universities cooperate to cultivate and absorb outstanding talents to build a wise tourism ecosphere in Guangdong-HongKong-Macao Big Bay. On the other hand, we can cooperate with social Internet enterprises and outsource some of our business to achieve mutual benefit and win-win situation.

There will inevitably be many obstacles in the process of the difference and cooperation between Guangdong, Hong Kong and Macao. Relevant departments will actively negotiate and discuss the appropriate scheme together positive aspects of mass communication.

\section{CONCLUSION}

Through the construction of smart tourism framework, different cities in Guangdong-HongKong-Macao Big Bay District can develop in a balanced and stable way. By introducing smart tourism, the structure of tourism industry can be upgraded, quality of products and services improved, effective government operation speed up. The differences in regulations and regulations are the challenges for the development. Local government organizations should face the problems with a win-win attitude, actively communicate, constantly adjust and improve.

\section{REFERENCES}

[1] He Wenjie, "Hong Kong-Zhuhai-Macao Bridge, Reconstructing the Tourism Development Pattern of Guangdong, Hong Kong and Macao”, China Tourism Daily, 2017, pp.10-19 (004).

[2] Anon, "The Financial Secretary Uses Budget Speech to Promote Diversified Economy and Boost Innovation and Technology”, Hong Kong Government News: 02-28.

[3] Zhang Yurong, "Macao: An Important Bridge between the Pearl River Delta and the World”, [J]. Well-off, 2017, pp.17: 48-49.

[4] Sun Gennian, Li Hong, Zhou Gongmei. (2016) Hong Kong society's emotional response to the surge in free travel and inbound tourism in the Mainland”, Economic Geography, 2016, pp. 182-188.

[5] Ren Hao, Zhang Mei, "Research on the construction of the western tourism industry ecosphere under the background of 'Internet +' ", ecological economy. 2016, pp. 110-114.

[6] Huang Sisi, “A review of domestic research on Intelligent Tourism [J]. Geography and geographic information science”, 2014, pp. 97-101.

[7] Qin Xue, Li Xiubin, “Obstacles and Path Choice of Tourism Cooperation between Guangdong, Hong Kong and Macao”, Reform and Strategy, 2010, pp. 138-141.

[8] World Bank Group, "East Asia's Changing Urban Landscape: Measuring a Decade of Spatial Growth”, Washington, DC: World Bank. 